\title{
The perfect storm: Disruptions to institutional delivery care arising from the COVID-19 pandemic in Nepal
}

\author{
Ashish KC ${ }^{1}$, Stefan Swartling Peterson ${ }^{1,2}$, Rejina \\ Gurung $^{1,3}$, Alkistis Skalkidou ${ }^{1}$, Jageshwar \\ Gautam $^{4}$, Honey Malla ${ }^{3}$, Punya Paudel ${ }^{5}$, Kumari \\ Bhattarai $^{5}$, Nisha Joshi ${ }^{5}$, Bhim Singh Tinkari ${ }^{5}$, \\ Shree Adhikari ${ }^{6}$, Durgalaxmi Shrestha ${ }^{7}$, Binda \\ Ghimire $^{8}$, Seema Sharma ${ }^{9}$, Laxmi Khanal ${ }^{10}$, \\ Sunil Shrestha ${ }^{10}$, Wendy Jane Graham ${ }^{11 *}$, \\ Mary Kinney ${ }^{12 *}$; on behalf of Nepal Neonatal \\ Network
}

\footnotetext{
${ }^{1}$ Department of Women's and Children's Health, Uppsala University, Sweden

${ }^{2}$ Department of Global Public Health, Karolinska Institute, Stockholm, Sweden

${ }^{3}$ Research Division, Golden Community, Lalitpur, Nepal ${ }^{4}$ Ministry of Health and Population, Kathmandu, Nepal ${ }^{5}$ Family Welfare Division, Department of Health Services, Nepal

${ }^{6}$ Paropakar Maternity and Women's Hospital, Nepal

${ }^{7}$ Bheri Hospital, Nepalgunj, Nepal

${ }^{8}$ Nepal Nursing Council, Kathmandu, Nepal

${ }^{9}$ Seti Provincial Hospital, Dhangadi, Nepal

${ }^{10}$ White Ribbon Alliance Nepal; Kathmandu

${ }^{11}$ London School of Hygiene \& Tropical Medicine, London, UK

${ }^{12} \mathrm{School}$ of Public Health, Faculty of Community and Health

Sciences, University of the Western Cape, Cape Town, South Africa

*Joint last authors.
}

\section{Correspondence to:}

Ashish KC

Department of Women's and Children's Health

Uppsala University

SE-751 85

Uppsala

Sweden

ashish.k.c@kbh.uu.se
Background The COVID-19 pandemic has led to system-wide disruption of health services globally. We assessed the effect of the pandemic on the disruption of institutional delivery care in Nepal.

Methods We conducted a prospective cohort study among 52356 women in nine hospitals to assess the disruption of institutional delivery care during the pandemic (comparing March to August in 2019 with the same months in 2020). We also conducted a nested follow up cohort study with 2022 women during the pandemic to assess their provision and experience of respectful care. We used linear regression models to assess the association between provision and experience of care with volume of hospital births and women's residence in a COVID-19 hotspot area.

Results The mean institutional births during the pandemic across the nine hospitals was 24563 , an average decrease of $11.6 \%(P<0.0001)$ in comparison to the same time-period in 2019. The institutional birth in high-medium volume hospitals declined on average by $20.8 \%(P<0.0001)$ during the pandemic, whereas in low-volume hospital institutional birth increased on average by $7.9 \%(P=0.001)$. Maternity services halted for a mean of 4.3 days during the pandemic and there was a redeployment staff to COVID-19 dedicated care. Respectful provision of care was better in hospitals with low-volume birth $(\beta=0.446, P<0.0001)$ in comparison to high-medium-volume hospitals. There was a positive association between women's residence in a COVID-19 hotspot area and respectful experience of care $(\beta=0.076, P=0.001)$.

Conclusions The COVID-19 pandemic has had differential effects on maternity services with changes varying by the volume of births per hospital with smaller volume facilities doing better. More research is needed to investigate the effects of the pandemic on where women give birth and their provision and experience of respectful maternity care to inform a "building-back-better" approach in post-pandemic period. 
The COVID-19 pandemic has placed unprecedented pressure on health systems globally. Preparedness and response for COVID-19 case management have acutely overwhelmed and strained routine health services, including maternity services $[1,2]$. with some devastating results. The early expectation that COVID-19 would have an indirect impact on maternal, newborn and child health services [3] has now been backed by mounting evidence that the pandemic has indeed led to the disruption of essential health services for women and their children during pregnancy, childbirth and postnatal period [4], with some devastating results [1,5-8].

Both the supply of and demand for maternity care have been impacted. Health facilities have undergone preparation and reorganization of their maternity services in order to triage and handle the COVID-19 cases [9]. Maternity health care workers have experienced extraordinary challenges, including lack of personal protective equipment, ever-changing or unclear clinical guidelines, harassment and violence, and overall increased workloads due to reallocation of staff to COVID-19 dedicated areas or self-isolation due to exposure or illness $[10,11]$. On the demand side, the COVID-19 era has also witnessed changes in care seeking behaviour $[5-8,12]$, with reports of delayed or reduced utilization of maternity services [5,13]. These delays result in adverse birth outcomes [14], and are compounded by issues of inequity [15]. The COVID-19 pandemic has exposed the health system fragility and has widened the equity gap for the most vulnerable population [16].

Maternity care and the progress made in maternal and newborn health (MNH) in the last 25 years are under threat due to the COVID-19 pandemic $[3,17]$. This progress includes health outcomes as well as a woman's right to high quality, dignified, respectful care $[18,19]$, as protected in global human rights law and policy [20,21] and laid out in the Respectful Maternity Care (RMC) Charter [22] and as recommended by the World Health Organization (WHO) [23,24]. Experience from other health crises, such as the Ebola outbreaks in West Africa, showed that quality and respectful care diminished and led to declines in facility deliveries [2527]. During the current pandemic, there has been widespread concern and some reporting about violations of RMC, such as unnecessary separation of women and their newborns, or denial of care $[1,4,28]$. The problem is exacerbated by health worker shortages and other health system strains as well as patient fear of exposure to the infection at the health facility $[4,29-31]$.

Our recent study from Nepal reports on the devastating impact of the national COVID-19 lockdown on maternity services, including increased risk of stillbirth and neonatal mortality as well as reduced facility births, increased risk of complications, and issues around the provision of quality care [15]. Prior to the COVID-19 pandemic, Nepal had been making remarkable strides to reduce maternal and perinatal mortality, yet there were still growing concerns of overcrowding in the higher-level referral facilities, under-utilization of the primary level referral facilities, and gaps in referral services between levels [32,33]. The global evidence of poor quality maternity care during the COVID-19 pandemic raises concern that there could also be an increase in disrespect and abuse in Nepal, despite policies protecting a woman's right to RMC [34].

To investigate this concern, we set out to understand the disruption of maternity services in Nepal due to the COVID-19 pandemic as well as to explore the provision and experience of institutional delivery care. We hypothesize that the arrival of COVID-19 created a perfect storm [35], wherein the disruptions to the health system, notably institutional maternity care, combined with existing challenges of referrals and sub-optimal utilization of services, created an unusual combination of events and circumstances resulting in reduced quality of maternity care (Figure S1 in the Online Supplementary Document).

\section{METHODS}

\section{Design}

We conducted a prospective cohort study in nine hospitals in Nepal where larger quality improvement studies, REFINE [36] and SUSTAIN [37] have been implemented since 2019. Our study assessed two components: 1) disruption in maternity services, and 2) respectful maternity care, defined as the provision and experience of institutional delivery care. For the first part, we compared the monthly trends in institutional births and bed occupancy rates in postnatal care units between two time periods, March-August 2019 and March-August 2020 (during the pandemic). There were 52356 women enrolled (27856 for March-August 2019 and 24500 for March-August 2020) and who consented to the REFINE and SUSTAIN studies. For the second component of the study, we conducted a nested cohort observational study as well as follow up interviews at 45 days with 2022 women who had a live birth at the hospitals during the pandemic to assess their provision and experience of institutional delivery care (Figure S2 in the Online Supplementary Document). 


\section{Settings}

Seven of the hospitals were secondary referral (provincial) level hospitals while two were primary referral (district) hospitals (Dadeldura and Surkhet). All hospitals provide Comprehensive and Emergency Obstetric and Neonatal Care services (CEmONC). The nine hospitals, distributed across all seven provinces, covered $11.2 \%$ of the national number of births for 2019 [36,37]. From March-August 2020, the Government of Nepal reported 39459 COVID-19 cases with wide variations across the provinces (Figures S3-6 in the Online Supplementary Document) and with a national lockdown imposed for this period.

\section{Study participants}

For the disruption of maternity services, we included all the women-infant pair consented and enrolled to REFINE [36] and SUSTAIN [37] studies. Women at 22 weeks of gestation or more admitted in the labour room with fetal heart sound at admission were eligible for this study. For the nested cohort study and follow up interviews, to measure the uptake and experience of care, a subset of women (10\%) who were part of the REFINE and SUSTAIN studies with live births (April 11-July 5, 2020) born either vaginally or caesarean births were enrolled and followed up at 45 days postpartum with a phone interview. To use the individual level data for this study, an additional approval was taken from the ethical review board of Nepal Health Research Council (reg No. 439/2020).

\section{Patient and public involvement}

This study aimed to assess the disruption of maternity services and respectful childbirth care during COVID-19. Since there is a need to redesign the health system so that there is a continuity of care during pandemics and disease outbreaks, the study was conducted together with health workers, health managers and policy makers.

\section{Data collection}

Data on institutional births was collected from the hospital record registry. The number of health workers in the labour and delivery room and those who were redeployed to COVID-19 area, and the number of days' maternity service were disrupted during the pandemic were assessed through observation from independent research nurses. The socio-demographic and provision of care data were extracted from the existing data collection system for REFINE and SUSTAIN studies. For these studies, a validated clinical observation checklist was used to observe the labour and delivery event for all vaginal births, and women's obstetric and neonatal information was collected from inpatient case notes. A data collection system was set up at each hospital, and independent clinical researchers did observations using a tablet-based application. To assess women's experience of care, a validated semi-structured questionnaire was used for follow up interviews with women by telephone at 45 days postpartum to assess their experience of care during childbirth [38].

\section{Measurement}

To assess the first component of the study, disruption of maternity services, we measured the institutional births before the pandemic (March-August 2019) and during pandemic (March-August 2020) by hospital. For each period, we measured the number of health workers in the labour and delivery room and the postnatal care bed occupancy rate (BOR) [39]. Specific to the period during the pandemic, we considered if hospitals had a dedicated COVID-19 space in the labour and delivery ward (ie, separate room) as well as if the hospital had reported any days of service disruption, ie, no maternity services provided for these days.

For the second component of the study, we considered respectful maternity care as the quality of maternity care during childbirth, considering both the provision and experience of care. To measure provision of care, we considered six components of the health worker's performance during intrapartum care based on WHO's 2016 "Standards for improving quality of maternal and newborn care in health facilities [23].": 1) health worker's hand washing practice before childbirth was defined as health care staff who did clean their hands correctly as per the WHO's five moments for hand hygiene, 2) health worker using gloves and gown to protect from infection transmission during childbirth, 3) preparation of equipment for birth, 4) health workers greet the mother at the time of admission, 5) newborn kept skin-to-skin contact with mother after birth, and 6) newborn breastfed within one hour of birth. To measure the experience of care, we considered six components from the woman's perspective based on the abuse and disrespect typology by Browser and Hill:[40] 1) verbal or physical abuse, 2) treated with dignity as measured by the health workers' sensitive handling of the perineal area, 3) delay or carelessness during the birth, 4) women's experience of care on any verbal or physical abuse, by health workers, 5) effective communication-a) health worker's informed and took consent before performing vaginal examination and b) women informed and consented before caesarean birth and 
6) supportive care to women a) women counselled on keeping the baby warm, b) women counselled on exclusive breast feeding and c) women counselled on newborn danger signs.

To assess the presence of a "COVID hotspot", women were asked at admission if they knew of any case of COVID-19 within the same community as their residence in the last seven days. If they indicated yes, then the participant was recorded as coming from a COVID hotspot area. None of the women were screened for COVID-19 infection upon admission during the pandemic period.

For socio-demographic characteristics, women's ethnicity was assessed based on the caste system [41] in Nepal (ie, relatively disadvantaged ethnic groups (Janajati, Madeshi, other disadvantaged, Dalit) and relatively advantaged ethnic groups (Brahmin and Chhetri-Hill, and Brahmin-Tarai). Women' age was assessed as a mean with standard deviation in each group and categorised as 18 years or younger, 19-24 years, 25-29 years, 30-34 years, and 35 years or older. Parity was measured as women who had no previous birth, at least one previous birth, or two or more previous births. Obstetric characteristics measures included: mode of birth including spontaneous vaginal birth, assisted vaginal birth and caesarean birth. For neonatal characteristics, we captured preterm birth less than 37 weeks of gestation based on first day of last menstrual period and sex of baby as boy or girl or ambiguous.

\section{Data analysis}

Hospitals were categorized into four groups based on the average number of daily deliveries during 2019 (Table S1 in the Online Supplementary Document): Group 1, low-volume delivery (1-8 births per day); Group 2, medium-volume delivery (9-16 births per day); Group 3, high-medium volume delivery (17-24 births per day); Group 4, high-volume delivery (25-33 births per day). To assess the disruption of maternity services, we calculated the average rate of change between the two time periods for the following measures: the institutional births and BOR. We used ANOVA test to assess the difference in institutional birth and BOR between two time periods. We calculated the mean difference for the number of health workers in the labour room and the number of days that the maternity services were disrupted. BOR was calculated as the number of postnatal beds occupied divided by the total number of postnatal beds available in the hospital multiplied by the number of days in the hospital (include time period), with the ratio multiplied by 100 [39].

The coverage of provision and experience of institutional delivery care were analysed among the cohort of women-infant pair for only the pandemic period. The differential factors affecting the provision of care were analysed based on residence in a COVID-19 hotspot area, the volume of deliveries per day, and complications during birth. The factors affecting experience of care were analysed by women's ethnicity, age category, parity, complications during admission, mode of birth, prematurity at birth, sex of child and the volume of deliveries per daily.

We created two continuous score indices, one for the respectful provision of care and one for the respectful experience of care, based on the above indicators, using principal component analysis (PCA). PCA is a dimension reduction technique used for combining many variables into a single one. The usual practice is to weight the variable according to the first principal component ie, the component that has the highest variance, and thus the highest discriminatory power. The provision and experience of care variables with coverage of $95 \%$ or less were included. The first principal component for respectful provision of care index had $40.5 \%$ variance, the highest variance, and was considered to measure the care. The first principal component for respectful experience of care index had $42.5 \%$ variance, highest variance, and was considered to the measure of care. The index score ranged from -2 to +2 , with former indicating poor provision or experience of care while the latter indicating good provision or respectful care.

We conducted bi-variate and multivariate linear regression to assess the association of respectful provision of care index and respectful experience of care index with four parameters: place of residence of women in relation to COVID-19 hotspots, socio-demographic characteristics, prematurity and volume of births per day. By analysing the data within these four parameters using the linear regression, we were able to assess the independent interaction of the social and obstetric characteristics with two separate indices. We used STATA 17.0 to manage and analyse the data (Stata Corp, College Station, TX, USA).

\section{RESULTS}

\section{Disruption of maternity services}

The mean number of institutional births in March-August 2019, 27793, decreased by $11.6 \%$ to 24563 $(P<0.0001)$ in the corresponding months of 2020. The average rate of change in institutional births between 
these two periods varied greatly by hospitals (Table 1). Six hospitals had a decline in births (range 10.5\% to 26.1\%); Pokhara had the greatest reduction. Three hospitals had an increase in monthly births (range 1.9\% to 23.7\%); Dadeldhura Hospital, a low-volume hospital, had the greatest increase in monthly births (23.7\%, $P<0.0001)$ whereas Seti Provincial Hospital, a high-medium volume hospital, declined by $26.6 \%(P=0.001)$ during the pandemic period. The average decline in the monthly births varied by the hospital group (volume of births) with the greatest reduction in Group 3 (high-medium volume hospitals) at 20.8\% $(P<0.001)$ and Group 2 (low-medium-volume hospitals) at 19.4\% $(P<0.001)$ during the pandemic but less declines in Group 4 (high-volume hospitals) at 4.3\% (P=0.033); and Group 1 (low-volume hospitals) at $7.9 \%(P=0.001)$ (Table S2 in the Online Supplementary Document).

Table 1. Disruption of maternity care services in the 9 hospitals of Nepal

\begin{tabular}{|c|c|c|c|c|c|c|c|c|c|c|c|}
\hline & 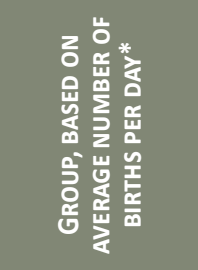 & 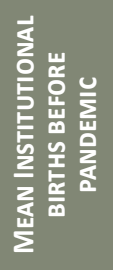 & 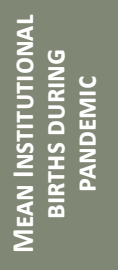 & 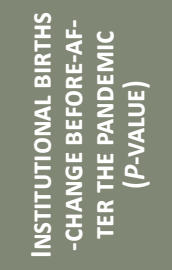 & 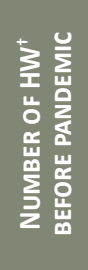 & 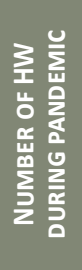 & 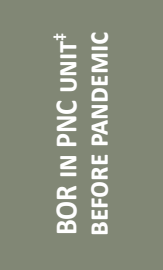 & 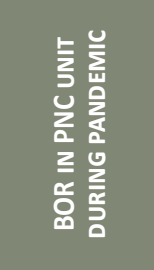 & 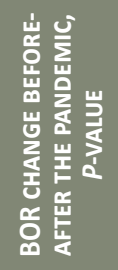 & 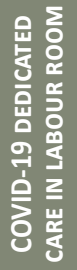 & 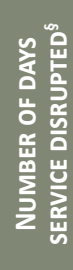 \\
\hline Overall & & 27793 & 24563 & $\begin{array}{c}-11.6 \% \\
(<0.0001)\end{array}$ & 6 & 5 & $\begin{array}{c}91.0 \% \\
(75.2,106.8)\end{array}$ & $\begin{array}{c}81.8 \% \\
(65.6,97.9) \\
\end{array}$ & 0.421 & Yes & 4.3 \\
\hline $\begin{array}{l}\text { Dadeldhura } \\
\text { hospital }\end{array}$ & $\begin{array}{l}\text { Group 1, low } \\
\text { volume }\end{array}$ & 582 & 720 & $\begin{array}{c}23.7 \% \\
(<0.0001)\end{array}$ & 4 & 4 & $\begin{array}{c}40.6 \% \\
(29.7,51.4)\end{array}$ & $\begin{array}{c}79.2 \% \\
(69.5,88.9)\end{array}$ & $<0.0001$ & Yes & 0 \\
\hline $\begin{array}{l}\text { Surkhet } \\
\text { Provincial }\end{array}$ & $\begin{array}{c}\text { Group 1, low } \\
\text { volume }\end{array}$ & 2047 & 2116 & $3.4 \%, 0.064$ & 4 & 4 & $\begin{array}{c}68.3 \% \\
(50.4,86.1) \\
\end{array}$ & $\begin{array}{c}68.6 \% \\
(56.5,80.6) \\
\end{array}$ & 0.976 & Yes & 0 \\
\hline $\begin{array}{l}\text { Bheri } \\
\text { Provincial }\end{array}$ & $\begin{array}{l}\text { Group 2, medi- } \\
\text { um volume }\end{array}$ & 2225 & 1900 & $\begin{array}{l}-14.6 \% \\
(<0.0001) \\
\end{array}$ & 6 & 6 & $\begin{array}{c}48.7 \% \\
(37.8,59.7) \\
\end{array}$ & $\begin{array}{c}45.2 \% \\
(35.1,55.4) \\
\end{array}$ & 0.651 & Yes & 3 \\
\hline $\begin{array}{l}\text { Seti } \\
\text { Provincial } \\
\text { hospital } \\
\end{array}$ & $\begin{array}{l}\text { Group 2, medi- } \\
\text { um volume }\end{array}$ & 2963 & 2189 & $\begin{array}{l}-26.1 \% \\
(<0.0001)\end{array}$ & 6 & 5 & $\begin{array}{c}43.7 \% \\
(36.4,51.0)\end{array}$ & $\begin{array}{c}25.9 \% \\
(22.9,28.9)\end{array}$ & 0.001 & Yes & 10 \\
\hline $\begin{array}{l}\text { Koshi } \\
\text { hospital }\end{array}$ & $\begin{array}{l}\text { Group 2, medi- } \\
\text { um volume }\end{array}$ & 3228 & 2691 & $\begin{array}{c}-16.6 \% \\
(<0.0001)\end{array}$ & 8 & 6 & $\begin{array}{c}69.4 \% \\
(51.9,86.9)\end{array}$ & $\begin{array}{c}52.3 \% \\
(40.2,64.3) \\
\end{array}$ & 0.141 & Yes & 8 \\
\hline $\begin{array}{l}\text { Janakapur } \\
\text { provincial }\end{array}$ & $\begin{array}{l}\text { Group 3, high } \\
\text { medium volume }\end{array}$ & 3111 & 2613 & $\begin{array}{l}-16.0 \% \\
(<0.0001)\end{array}$ & 6 & 6 & $\begin{array}{l}117.1 \% \\
(100.9 \\
133.3)\end{array}$ & $\begin{array}{c}42.7 \% \\
(27.6,57.8)\end{array}$ & $<0.0001$ & Yes & 3 \\
\hline Pokhara & $\begin{array}{l}\text { Group } 3, \text { high } \\
\text { medium volume }\end{array}$ & 3414 & 2554 & $\begin{array}{c}-25.2 \% \\
(<0.0001) \\
\end{array}$ & 6 & 4 & $\begin{array}{c}79.4 \% \\
(60.4,98.5) \\
\end{array}$ & $\begin{array}{c}57.6 \% \\
(42.6,72.6) \\
\end{array}$ & -0.104 & Yes & 6 \\
\hline Bharatpur & $\begin{array}{l}\text { Group } 4 \text {, high } \\
\text { volume }\end{array}$ & 5175 & 4634 & $\begin{array}{l}-10.5 \% \\
(0.032)\end{array}$ & 8 & 8 & $\begin{array}{l}196.1 \% \\
(144.4 \\
247.7)\end{array}$ & $\begin{array}{l}182.7 \% \\
(155.5 \\
209.9)\end{array}$ & 0.66 & Yes & 6 \\
\hline $\begin{array}{l}\text { Lumbini } \\
\text { provincial }\end{array}$ & $\begin{array}{l}\text { Group 4, high } \\
\text { volume }\end{array}$ & 5048 & 5146 & $1.9 \%,(0.453)$ & 8 & 6 & $\begin{array}{l}155.4 \% \\
(122.7 \\
188.1)\end{array}$ & $\begin{array}{l}181.6 \% \\
(143.2 \\
220.0)\end{array}$ & 0.327 & Yes & 3 \\
\hline
\end{tabular}

HW - health worker, BOR - bed occupancy rate, PNC - postnatal care

*Group 1 (1-8 births per day); Group 2 (9-16 births per day); Group 3 (17-24 births per day); Group 4 (25-33 births per day).

$\uparrow$ Number of health workers per $24 \mathrm{~h}$ in the labour room.

\#Bed occupancy rate in the postnatal unit.

$\S$ Number of days that maternity services were not provided.

The average BOR across the nine facilities in their postnatal units declined from 91.0\% (95\% CI; 75.2, 106.8) before the pandemic to $81.8 \%(95 \% \mathrm{CI}=65.6,97.9)$ during the pandemic $(P=0.421)$. Again, Dadeldhura had the greatest BOR increase ( $40.6 \%$ to $79.2 \%, P<0.0001$ ), and Seti had the second greatest decrease in BOR ( $43.7 \%$ to $25.9 \%, P=0.001$ ), Janakpur had the overall greatest BOR decrease ( $117.1 \%$ to $42.7 \%, P<0.001$ ). The BOR for Group 3 (high-medium volume) hospitals had the greatest decrease during the pandemic (98.3\% to $50.1 \%, P<0.0001$ ) and Group 4 (high-volume) hospitals reported over 100\% capacity (Table S3 in the Online Supplementary Document). All of the hospitals reported a dedicated room in the labour and delivery ward for COVID-19.

Before the pandemic, the number of health workers per 24 hours in the labour room ranged from four to eight across the hospitals with an average of 6.2 health workers. This staffing level decreased to 5.4 health workers during the pandemic period due to the redeployment of staff to COVID-19 dedicated care. Three hospitals had a reduction of two health workers during the pandemic (Koshi, Pokhara and Lumbini) but no changes 
took place in the Group 1 hospitals (low-volume). Maternity services were halted for an average of 4.3 days during the pandemic because of a disease outbreak in the labour room (range from 0 to 10 days) over the period March-August 2020. Seti hospital reported the largest number of days disrupted, 10 days, but no disruptions at all were reported in Dadeldhura and Surkhet (Table 1).

\section{Respectful provision of care during childbirth during COVID-19}

Table 2 presents the coverage of indicators measuring the provision of care. Health workers washed hands before attending to a delivery in $52.0 \%$ of the births. The coverage was higher for deliveries among women who arrived from a COVID-19 hotspot area than those from non-hotspot areas (60.2\% vs 41.9\%). The coverage of handwashing before childbirth was highest in the lower volume hospitals and lowest in the highest volume hospitals. Preparation of equipment for immediate newborn care occurred in $86.4 \%$ of births, with higher coverage in the lower volume hospitals. Across all hospitals, 33.6\% of women were greeted upon admission, again with higher coverage among women from lower volume facilities. The coverage of women greeted upon admission was higher among women who arrived from a COVID-19 hotspot area than those from non-hotspot areas (44.8\% vs 23.3\%).

Table 2. Coverage of provision of care and co-variate variance

\begin{tabular}{|c|c|c|c|c|c|c|}
\hline & $\begin{array}{l}\text { HEALTH WORKERS } \\
\text { WASHES HAND BE- } \\
\text { FORE CHILDBIRTH }\end{array}$ & $\begin{array}{l}\text { HEALTH WORKERS } \\
\text { USES GLOVES ON } \\
\text { BOTH HAND AND } \\
\text { GOWN }\end{array}$ & $\begin{array}{l}\text { PREPARATION OF } \\
\text { EQUIPMENT FOR } \\
\text { IMMEDIATE NEW- } \\
\text { BORN CARE }\end{array}$ & $\begin{array}{l}\text { HEALTH WORKERS } \\
\text { GREET MOTHERS }\end{array}$ & $\begin{array}{l}\text { BABY KEPT SKIN } \\
\text { TO SKIN CONTACT }\end{array}$ & $\begin{array}{l}\text { BREAST FEEDING } \\
\text { INITIATED INSIDE } \\
\text { LABOUR ROOM }\end{array}$ \\
\hline Overall coverage of care & $52.0 \%(48.9,55.1)$ & $97.8 \%(96.7,98.6)$ & $86.4 \%(84.1,88.4)$ & $33.6 \%(30.7,36.6)$ & $21.5 \%(19.0,24.2)$ & $48.4 \%(45.3,51.6)$ \\
\hline \multicolumn{7}{|l|}{ COVID-19 area: } \\
\hline Yes & $60.2(55.5,64.8)$ & $94.1(91.3,96.0)$ & $85.2(81.5,88.3)$ & $44.8(40.1,49.6)$ & $21.2(17.4,25.6)$ & $44.8(39.9,49.8)$ \\
\hline No & $41.9(38.0,45.9)$ & $90.9(88.3,93.0)$ & $77.8(74.3,80.9)$ & $23.3(20.0,26.8)$ & $21.5(18.3,25.2)$ & $49.7(45.5,53.9)$ \\
\hline \multicolumn{7}{|l|}{ Number of daily births: } \\
\hline Group 1, 1-8 births & $77.1(69.5,83.2)$ & $95.8(91.0,98.1) *$ & $96.5(91.9,98.6)$ & $56.9(48.7,64.8)$ & $14.9(9.9,21.8)$ & $48.9(40.8,57.2)$ \\
\hline Group 2, 9-16 births & $50.8(46.4,55.3)$ & $94.2(91.8,96.0)^{*}$ & $88.7(85.5,91.2)$ & $37.7(33.5,42.1)$ & $19.1(15.7,23.0)$ & $46.7(42.2,51.3)$ \\
\hline Group 3, 17-24 births & $40.1(34.8,45.7)$ & $89.2(85.2,92.2) *$ & $69.8(64.4,74.6)$ & $19.8(15.7,24.5)$ & $27.4(22.4,33.0)$ & $52.2(46.3,58.1)$ \\
\hline Group 4, 25-33 births & $33.3(25.5,42.3)$ & $89.2(82.2,93.6) *$ & $61.7(52.7,69.9)$ & $11.7(7.0,18.6)$ & $25.5(18.1,34.6)$ & $45.3(36.1,54.8)$ \\
\hline \multicolumn{7}{|c|}{ No complication during admission: } \\
\hline No & $49.9(46.8,53.0)$ & $93.2(91.4,94.6)$ & $81.8(79.2,84.1)$ & $32.5(29.6,35.5)$ & $20.7(18.2,23.5)$ & $48.4(45.2,51.7)$ \\
\hline Yes & $41.5(31.3,52.4)$ & $82.9(73.2,89.6)$ & $73.2(62.6,81.6)$ & $26.8(18.4,37.4)$ & $31.8(21.7,43.9)$ & $48.5(36.7,60.4)$ \\
\hline
\end{tabular}

In a bi-variate analysis of the associations with the respectful provision of care index, shown using box plots, respectful provision of care was greater among women arriving from COVID hotspot areas than

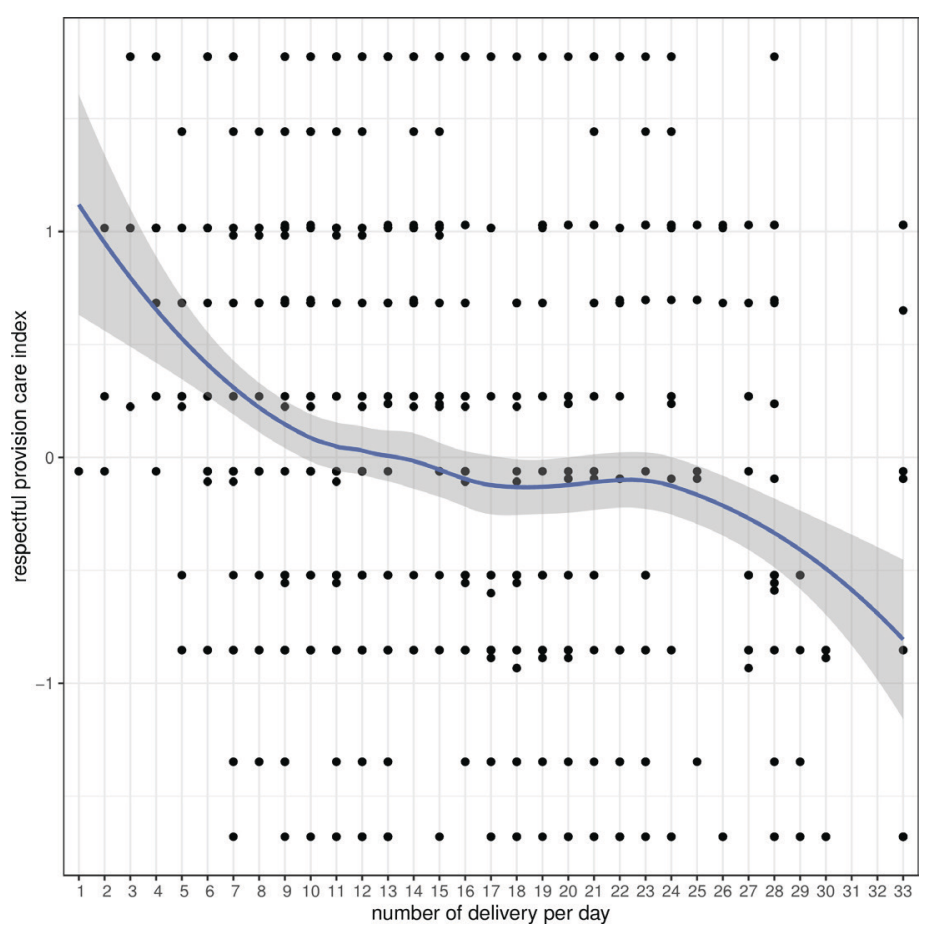

Figure 1. Respectful provision of care by volume of birth. those who did not arrive from a COVID hotspot area. A higher respectful provision of care score was found among the multi-parous women than first time mothers (Figure S6 in the Online Supplementary Document). There was also a higher score for the respectful provision of care among preterm babies and for Group 1 hospitals (low-volume) (Figure S7 in the Online Supplementary Document). With each increase in the average number of institutional births per day, there was a decline in the respectful provision of care score (Figure 1).

Using the multi-variate linear regression analysis, there was an increase in respectful provision of care with women coming from a COVID hotspot area $(\beta=0.275, P<0.0001)$ in reference to women not coming from a COVID hotspot area. The respectful provision of care was better with number of daily births limited to Group 1 (low-volume) hospitals ( $\beta=0.446$, $P<0.0001$ ) in reference to Group 3 (high-medium volume) hospitals. The respectful provision of care was less in Group 5 (high-volume) hospitals ( $\beta=-0.335$, $P=0.002$ ) in reference to Group 3 (high-medium volume) hospitals (Table 3). 
Table 3. Bi-variate and multi-variate linear regression on the association between co-variates and respectful provision care index during COVID-19 period

\begin{tabular}{|c|c|c|c|c|c|c|}
\hline & \multicolumn{3}{|c|}{ BI-VARIATE ANALYSIS } & \multicolumn{3}{|c|}{ MULTI-VARIATE ANALYSIS } \\
\hline & $\beta$ estimate & t-value & $P$-value & $\beta$ estimate & t-value & $\boldsymbol{P}$-value \\
\hline Global intercept & & & & -0.247 & -4.042 & 0 \\
\hline \multicolumn{7}{|c|}{ Women's arrival from COVID-19 hotspot } \\
\hline Intercept & -0.132 & -2.996 & 0.003 & & & \\
\hline No & Reference & & & Reference & & \\
\hline Yes & 0.308 & 4.636 & $<0.0001$ & 0.275 & 4.172 & $<0.0001^{*}$ \\
\hline \multicolumn{7}{|c|}{ Volume of births per day in the hospital: } \\
\hline Intercept & 0.048 & 0.993 & 0.321 & & & \\
\hline Group 1, 1-8 births per day & 0.391 & 3.982 & $<0.0001$ & 0.446 & 3.903 & $<0.0001^{*}$ \\
\hline Group 2, 9-16 births per day & Reference & & & 0.087 & 1.127 & 0.26 \\
\hline Group 3, 17-24 births per day & -0.172 & -2.228 & 0.026 & Reference & & \\
\hline Group 4, 25-33 births per day & -0.488 & -4.498 & $<0.0001$ & -0.335 & -3.149 & $0.002 *$ \\
\hline \multicolumn{7}{|l|}{ Complication during admission: } \\
\hline Intercept & -0.007 & -0.202 & 0.84 & & & \\
\hline No & Reference & & & Reference & & \\
\hline Yes & 0.103 & 0.773 & 0.439 & 0.147 & 1.133 & 0.258 \\
\hline
\end{tabular}

\section{Respectful experience of care during COVID-19}

Table 4 presents the coverage of indicators measuring the experience of care. The vast majority of women reported no verbal or physical abuse (95.4\%) and no delay or carelessness (91.4\%). No one reported discrimination during childbirth and most women were informed and consented for caesarean birth (95.6\%). Counselling indicators had lower coverage, with $40.0 \%$ of women reporting they were counselled on keeping the newborn warm, $44.1 \%$ of women counselled on exclusive breastfeeding and $15.3 \%$ of women counselled on newborn danger signs. Consent before performing vaginal examination was higher among primiparous women than nulliparous women ( $55.3 \%$ vs $44.3 \%$ ). The counselling to women on keeping the baby warm was higher among multi-parous women than first time women (47.9\% vs 36.3\%). Group 1 hospitals (low-volume) had a higher proportion of women who were consented for vaginal examination than the other groups (Table 4).

Table 4. Coverage of experience of care and co-variate variance

\begin{tabular}{|c|c|c|c|c|c|c|}
\hline & CONSENT FOR PV & $\begin{array}{l}\text { INFORMED BEFORE } \\
\text { EMERGENCY CS }\end{array}$ & $\begin{array}{l}\text { NO DELAY OR } \\
\text { CARELESSNESS OR } \\
\text { IGNORED DURING } \\
\text { THE CARE }\end{array}$ & $\begin{array}{l}\text { COUNSELLING ON } \\
\text { KEEPING THE BABY } \\
\text { WARM }\end{array}$ & $\begin{array}{l}\text { COUNSELLING ON } \\
\text { EXCLUSIVE BREAST } \\
\text { FEEDING }\end{array}$ & $\begin{array}{l}\text { COUNSELLING ON } \\
\text { NEWBORN DANGER } \\
\text { SIGNS }\end{array}$ \\
\hline Overall coverage of care & $50.2 \%(48.1,52.4)$ & $95.6 \%(93.5,97.1)$ & $91.4 \%(90.1,92.6)$ & $40.0 \%(37.9,42.2)$ & $44.1 \%(42.0,46.3)$ & $15.3 \%(13.8,16.9)$ \\
\hline \multicolumn{7}{|l|}{ Ethnicity: } \\
\hline Dalit, relatively disadvantaged & $49.8(43.5,56.1)$ & $93.9(82.6,98.0)$ & $91.6(87.3,94.5)$ & $35.4(29.6,41.7)$ & $43.5(37.3,49.9)$ & $15.2(11.2,20.4)$ \\
\hline $\begin{array}{l}\text { Janajati, relatively } \\
\text { disadvantaged }\end{array}$ & $48.3(44.3,52.3)$ & $98.2(94.4,99.4)$ & $91.4(88.9,93.4)$ & $37.4(33.6,41.3)$ & $41.9(38.0,45.9)$ & $11.5(9.1,14.3)$ \\
\hline $\begin{array}{l}\text { Madhesi, relatively } \\
\text { disadvantaged }\end{array}$ & $46.8(42.1,51.5)$ & $89.4(80.9,94.4)$ & $89.8(86.6,92.3)$ & $35.2(30.8,39.8)$ & $44.9(40.3,49.6)$ & $15.5(12.4,19.2)$ \\
\hline $\begin{array}{l}\text { Muslim, relatively } \\
\text { disadvantaged }\end{array}$ & $38.8(29.1,49.5)$ & $84.2(60.8,94.8)$ & $90.6(82.3,95.2)$ & $40.0(30.2,50.7)$ & $47.1(36.7,57.7)$ & $12.9(7.3,21.9)$ \\
\hline $\begin{array}{l}\text { Brahmin/Chhetri, relatively } \\
\text { advantaged }\end{array}$ & $55.9(52.1,59.7)$ & $98.3(95.0,99.5)$ & $92.5(90.2,94.3)$ & $47.2(43.3,51.0)$ & $45.0(41.2,48.8)$ & $18.6(15.8,21.8)$ \\
\hline Other, relatively advantaged & $52.0(33.1,70.4)$ & $90.0(53.2,98.6)$ & $96.0(76.4,99.4)$ & $44.0(26.3,63.4)$ & $56.0(36.6,73.7)$ & $24.0(11.2,44.2)$ \\
\hline \multicolumn{7}{|l|}{ Age category (years): } \\
\hline $15-19$ & $48.7(40.8,56.6)$ & $82.8(64.6,92.7)$ & $92.8(87.4,96.0)$ & $33.6(26.5,41.4)$ & $40.1(32.6,48.1)$ & $11.8(7.6,18.0)$ \\
\hline $20-24$ & $49.0(45.8,52.2)$ & $95.3(91.4,97.4)$ & $92.5(90.6,94.0)$ & $39.6(36.5,42.7)$ & $46.8(43.6,50.0)$ & $15.9(13.7,18.4)$ \\
\hline $25-29$ & $51.6(47.8,55.5)$ & $98.3(94.9,99.5)$ & $89.8(87.2,91.9)$ & $38.7(35.0,42.5)$ & $41.2(37.4,45.0)$ & $13.2(10.7,16.0)$ \\
\hline $30-34$ & $53.1(46.6,59.6)$ & $95.8(87.7,98.6)$ & $91.5(87.1,94.5)$ & $47.8(41.3,54.3)$ & $45.1(38.7,51.7)$ & $18.3(13.8,23.9)$ \\
\hline$\geq 35$ & $48.4(36.3,60.7)$ & $94.1(67.9,99.2)$ & $88.7(78.2,94.5)$ & $48.4(36.3,60.7)$ & $40.3(28.9,52.9)$ & $25.8(16.5,38.1)$ \\
\hline \multicolumn{7}{|l|}{ Parity: } \\
\hline No previous birth & $44.3(40.9,47.8)$ & $93.9(90.0,96.4)$ & $91.8(89.6,93.5)$ & $36.3(33.0,38.8)$ & $43.5(40.1,47.0)$ & $12.9(10.8,15.4)$ \\
\hline 1 previous birth & $55.3(51.7,58.9)$ & $98.8(95.3,99.7)$ & $91.2(88.9,93.1)$ & $38.6(35.1,42.1)$ & $42.1(38.6,45.7)$ & $14.0(11.7,16.7)$ \\
\hline 2 or more previous birth & $52.3(47.9,56.6)$ & $94.4(88.2,97.5)$ & $91.2(88.5,93.4)$ & $47.9(43.6,52.3)$ & $47.9(43.6,52.3)$ & $20.9(17.5,24.7)$ \\
\hline
\end{tabular}


Table 4. Continued

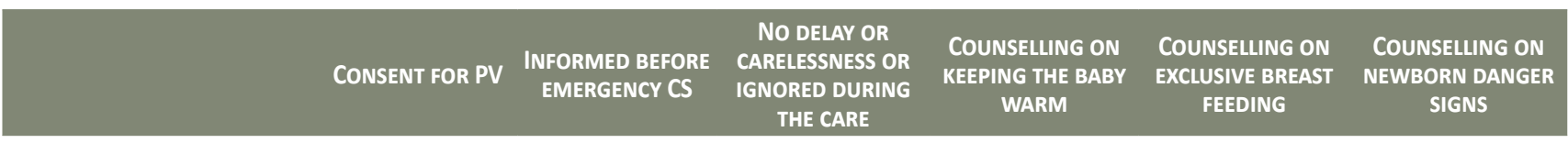

Complication during admission:

\begin{tabular}{|c|c|c|c|c|c|c|}
\hline No & $49.6(47.3,51.9)$ & $95.0(92.3,96.7)$ & $91.1(89.6,92.3)$ & $39.5(37.3,41.8)$ & $43.6(41.3,45.9)$ & $15.2(13.6,17.0)$ \\
\hline Yes & $55.3(48.9,61.6)$ & $98.1(92.8,99.5)$ & $94.5(90.7,96.8)$ & $43.8(37.6,50.2)$ & $48.1(41.8,54.5)$ & $15.7(11.6,21.0)$ \\
\hline \multicolumn{7}{|l|}{ Mode of delivery: } \\
\hline Spontaneous vaginal delivery & $45.5(43.0,48.1)$ & NA & $90.9(89.4,92.3)$ & $38.6(36.2,41.2)$ & $43.5(41.0,46.1)$ & $15.1(13.4,17.0)$ \\
\hline Instrumental delivery & $50.0(37.6,62.4)$ & NA & $95.0(85.6,98.4)$ & $46.7(34.5,59.2)$ & $41.7(29.9,54.4)$ & $13.3(6.8,24.5)$ \\
\hline Caesarean birth & $64.0(59.7,68.0)$ & $95.6(93.5,97.1)$ & $92.5(89.8,94.5)$ & $43.2(38.9,47.5)$ & $46.1(41.8,50.5)$ & $16.0(13.1,19.5)$ \\
\hline \multicolumn{7}{|l|}{ Sex: } \\
\hline Boy & $51.5(48.6,54.5)$ & $95.8(92.7,97.6)$ & $92.2(90.5,93.6)$ & $42.6(39.7,45.5)$ & $45.1(42.2,48.0)$ & $16.4(14.3,18.7)$ \\
\hline Girl & $48.7(45.5,52.0)$ & $95.4(91.7,97.5)$ & $90.6(88.5,92.3)$ & $36.9(33.8,40.1)$ & $43.0(40.0,46.2)$ & $13.8(11.7,16.2)$ \\
\hline Ambiguous & 0 & 100 & 0 & 0 & 0 & 100 \\
\hline \multicolumn{7}{|l|}{ COVID-19 hotspot: } \\
\hline No & $50.5(47.6,53.4)$ & $96.2(93.3,97.9)$ & $91.8(90.1,93.3)$ & $38.4(35.6,41.2)$ & $44.7(41.9,47.6)$ & $15.1(13.1,17.2)$ \\
\hline Yes & $50.1(46.5,53.6)$ & $94.8(90.5,97.2)$ & $91.3(89.1,93.1)$ & $41.1(37.7,44.6)$ & $41.8(38.3,45.3)$ & $15.8(13.4,18.6)$ \\
\hline \multicolumn{7}{|l|}{ Number of daily births: } \\
\hline Group 1, 1-8 births & $63.4(58.0,68.5)$ & $98.6(90.6,99.8)$ & $93.9(90.7,96.0)$ & $60.9(55.5,66.1)$ & $62.2(56.8,67.3)$ & $28.6(24.0,33.8)$ \\
\hline Group 2, 9-16 births & $48.4(45.0,51.8)$ & $93.1(88.7,95.9)$ & $89.7(87.4,91.6)$ & $37.2(33.9,40.5)$ & $42.6(39.3,46.1)$ & $15.6(13.3,18.2)$ \\
\hline Group 3, 17-24 births & $47.0(43.1,50.9)$ & $97.2(93.3,98.8)$ & $92.4(90.1,94.2)$ & $33.4(29.8,37.2)$ & $40.0(36.3,43.9)$ & $9.5(7.4,12.0)$ \\
\hline Group 4, 25-33 births & $47.5(41.3,53.8)$ & $96.4(86.6,99.1)$ & $91.8(87.6,94.7)$ & $38.9(33.0,45.2)$ & $35.7(29.9,41.9)$ & $11.5(8.0,16.1)$ \\
\hline
\end{tabular}

$\mathrm{PV}$ - per vaginal examination, CS - caesarean section

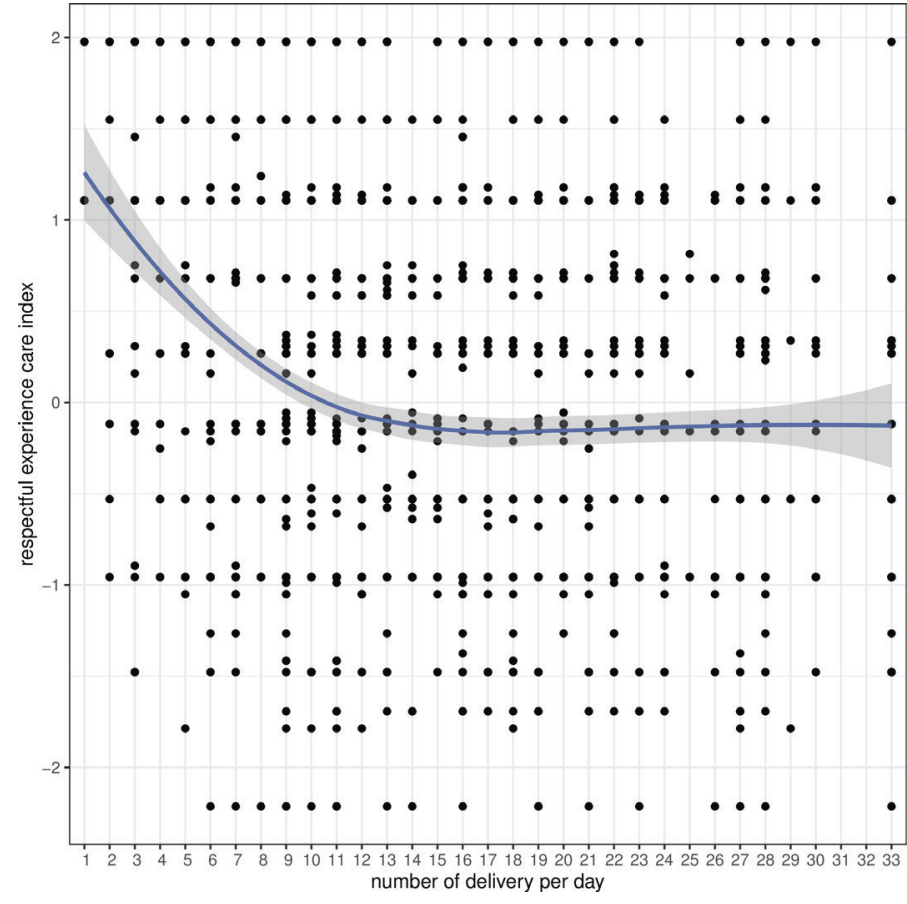

Figure 2. Respectful experience of care by volume of birth.
In a bi-variate analysis on associations with the respectful experience of care index, the score was highest in Group 1 (low-volume) hospitals and lowest in Group 3 (high-medium volume) hospitals (Figure S9 in the Online Supplementary Document). With each increase in the average number of institutional births per day, there was a decline in the respectful experience of care score (Figure 2).

Using multi-variate linear regression analysis, there was an increase in respectful experience of care for women coming from a hotspot area $(\beta=0.076, P=0.001)$ in reference to women not coming from a hotspot area. Women from Janjati, a relatively disadvantaged ethnic group, had an inverse association with the respectful experience of care $(\beta=-0.184, P=0.001)$. Women who had two or more previous births reported better experience of respectful care $(\beta=0.175, P=0.003)$ compared to those with no previous birth. Women who had a caesarean birth reported better care $(\beta=0.194, P<0.0001)$ as compared to women who had a spontaneous vaginal birth. Women with preterm birth reported more respectful care $(\beta=0.188$; $P=0.002)$ in reference with term birth. The respectful experience of care was better in Group 1 (low-volume) hospitals $(\beta=0.549, P<0.0001)$ in reference to Group 3 (high-medium volume) hospitals (Table 5).

\section{DISCUSSION}

The COVID-19 pandemic has disrupted maternity services unevenly in Nepal. During the pandemic, medium-volume hospitals experienced the greatest average rates of declines in institutional births; while conversely low-volume hospitals experienced an increase in institutional births. Maternity services halted on average by 4.3 days, and the number of health workers per labour room in 24 hours reduced. BOR in the postnatal care units declined in all but the three hospitals that also had increases in institutional births. Our investigation on the provision and experience of childbirth during the pandemic found that women received better respectful maternity care in the lower volume hospitals as compared to the medium-high volume hospitals. 
Table 5. Bi-variate and multi-variate linear regression on the association between co-variates and respectful experience care index during COVID-19 period

\begin{tabular}{|c|c|c|c|c|c|c|}
\hline & \multicolumn{3}{|c|}{ BI-VARIATE LINEAR REGRESSION } & \multicolumn{3}{|c|}{ MULTI-VARIATE LINEAR REGRESSION } \\
\hline & $\beta$ coefficient & t-value & $P$-value & $\beta$ coefficient & t-value & $P$-value \\
\hline Global intercept & & & & -0.039 & -0.599 & 0.549 \\
\hline \multicolumn{7}{|l|}{ Ethnicity: } \\
\hline Intercept & 0.125 & 3.206 & 0.001 & & & \\
\hline Dalit & -0.162 & -2.143 & 0.032 & -0.164 & -2.159 & 0.031 \\
\hline Janajati & -0.215 & -3.799 & $<0.0001$ & -0.184 & -3.273 & $0.001 *$ \\
\hline Madhesi & -0.173 & -2.79 & 0.005 & -0.221 & -3.392 & $0.001 *$ \\
\hline Muslim & -0.176 & -1.534 & 0.125 & -0.282 & -2.398 & 0.017 \\
\hline Brahmin/Chhetri & Reference & & & Reference & & \\
\hline Others & 0.085 & 0.418 & 0.676 & -0.064 & -0.322 & 0.747 \\
\hline \multicolumn{7}{|l|}{ Parity: } \\
\hline Intercept & -0.084 & -2.371 & 0.018 & & & \\
\hline No previous birth & Reference & & & Reference & & \\
\hline 1 previous birth & 0.07 & 1.377 & 0.169 & 0.005 & 0.09 & 0.928 \\
\hline 2 or more previous birth & 0.236 & 4.147 & $<0.0001$ & 0.175 & 2.94 & $0.003 *$ \\
\hline \multicolumn{7}{|l|}{ Mode of birth: } \\
\hline Intercept & -0.045 & -1.712 & 0.087 & & & \\
\hline Spontaneous vaginal birth & Reference & & & Reference & & \\
\hline Assistant vaginal birth & 0.066 & 0.505 & 0.614 & 0.062 & 0.473 & 0.636 \\
\hline Caesarean birth & 0.171 & 3.325 & 0.001 & 0.194 & 3.774 & $<0.0001^{*}$ \\
\hline \multicolumn{7}{|l|}{ Preterm birth: } \\
\hline Intercept & -0.035 & -1.441 & 0.15 & & & \\
\hline No & Reference & & & Reference & & \\
\hline Yes & 0.205 & 3.483 & 0.001 & 0.188 & 3.13 & $0.002 *$ \\
\hline \multicolumn{7}{|l|}{ COVID-19 hotspot area: } \\
\hline Intercept & -0.006 & -0.212 & 0.832 & & & \\
\hline No & Reference & & & Reference & & \\
\hline Yes & -0.004 & -0.09 & 0.928 & -0.042 & -0.943 & 0.346 \\
\hline \multicolumn{7}{|l|}{ Number of daily births: } \\
\hline Intercept & -0.056 & -1.652 & 0.099 & & & \\
\hline Group 1, 1-8 births per day & 0.573 & 8.984 & $<0.0001$ & 0.549 & 8.3 & $<0.0001^{*}$ \\
\hline Group 2, 9-16 births per day & Reference & & & Reference & & \\
\hline Group 3, 17-24 births per day & -0.089 & -1.722 & 0.085 & -0.083 & -1.514 & 0.13 \\
\hline Group 4, 25-33 births per day & -0.068 & -0.964 & 0.335 & -0.076 & -1.012 & 0.312 \\
\hline
\end{tabular}

Since hospitals with fewer institutional births provided better provision and experience of care, greater consideration is needed to look at the volume of deliveries as an indication of providing respectful maternity care. The 2005 big strategy shift from home to health facilities for childbirth has been a lauded success in Nepal [42]; yet the distribution of births across facilities may be influencing respectful care. Prior to COVID-19, our study shows that some hospitals were already overburdened with large volumes of births and overcrowding, in some cases with nearly 200\% BOR rates and with one health worker delivering an average of 1000 women per year. The association between overcrowding and poor provision and experience of care has been argued by others in Nepal [43] and elsewhere [44,45], and is reinforced by our study. Before the pandemic, by-passing of the primary referral health facilities (low-volume) was already a challenge in Nepal leading to overcrowding at the higher level facilities (medium-and high-volume) [32,44,46].

Our study revealed an increase in the monthly births at the low-volume hospitals (Dadeldhura and Surkhet Provincial) during the pandemic, which are first referral units as compared to their medium-volume hospitals (Bheri Provincial and Seti Provincial), which are secondary referral units. This could be an indication that women may have decided to seek care at the referral units closer to home than secondary referral units. Our study also showed that fewer women delivered in these hospitals. Studies from India have also reported reduced institutional births at tertiary care centres and a decrease in referral cases during the pandemic $[5,6]$. Reduced health care seeking behaviour of pregnant women was also observed in a study from Ghana during the pandemic [47]. There is an urgent need to identify where these women have given birth instead, and what sort of care these women and newborns have received. Understanding why these changes have taken place also needs to be explored. Women might have apprehension for institutional deliveries due to fears of con- 
tracting the SARS-CoV2 virus or due to lack of transportation facilities in Nepal [13], but more investigation is needed. There also remains a large gap in our knowledge around how respectful maternity care has influenced where women access maternity care.

While we observed that the respectful provision as well as experience of care was better with a decline in monthly institutional births, the coverage of some respectful maternity care indicators was still unacceptably low. Half of the women were not consented for vaginal examination; one in twenty women felt ignored during childbirth; only one in five newborns were kept skin to skin with their mothers after birth; and only half of newborns were breastfed within 30 minutes. A four-country (Asia and Africa) assessment of mistreatment during childbirth using clinical observation and follow up surveys revealed similar findings [48]. However, a three country (Africa) assessment of newborn care reported variable results for immediate skin-to-skin care (64.4\% vs our $21.5 \%$ ) [49]. and a multi-country study reported lower rates of breastfeeding within 30 minutes (23.9\% vas our $48.4 \%$ ) [50]. Provision of high-quality maternity care, including positive care experiences for women, must remain an increasing priority in global health, especially as more women [22] give birth in health facilities [51] and systems undergo redesign [33].

Our study did not support the concern that women from places reporting COVID-19 cases might receive poorer care due to stigmatization or fears of contracting the SARS-CoV2 [4]. In fact, we found the opposite. Respectful maternity care was better among women who came from COVID-19 hotspot areas, with observations showing better immediate newborn care practice, such as babies being kept in skin to skin contact with the mother and being breastfed within 1 hour. Women from these areas also reported experiencing better counselling on breast feeding, keeping the baby warm, and care-seeking for any newborn danger sign. More investigation is needed to understand why women from COVID-19 hotspots received better care.

Just prior to the COVID-19 pandemic, Roder-DeWan and colleagues called for a health system redesign of MNH services in low and middle-income countries, strengthening primary level referral facilities to provide comprehensive services, reducing overcrowding in high-level referral facilities, and providing the care needed to women closer to home [44]. The COVID-19 pandemic may actually provide an opportunity for health systems to reimagine their systems to do this as evidence from our study and others have shown reduction in institutional deliveries at higher-level facilities overall [5,7]. However, the change in the pattern of utilization of primary and secondary referral hospitals during the pandemic demonstrated in this study provides new information on the opportunity for future redesign and strengthening of services [33]. Understanding factors that influenced these changes will be key to re-building confidence in the health system after the COVID-19 pandemic.

\section{Limitations}

This study has several limitations. None of the women admitted to the nine hospitals were tested for COVID-19, so we do not know the prevalence of the virus in this population. Another limitation is that the study was only able to examine the experience during the COVID-19 outbreak and not before. The information about women from COVID-19 hotspot areas was based on interviews, and might be subject to reporting bias. The study did not explore why women selected the facilities where they gave birth, nor did it explore women's previous experience with the health system. The observations were only done for vaginal births, not caesarean sections. This study also has several strengths, including examining both the provision and experience of care during the COVID-19 era. Prospective data collection using trained researchers to collect information using observation checklist and semi-structured questionnaire strengthens confidence in these findings.

\section{CONCLUSION}

The COVID-19 pandemic has had differential effects on maternity services, with a sharp decline in births at high and medium-volume hospitals but an increase in births at low-volume hospitals. This signifies marked changes in where women sought maternity care during the pandemic and more research is needed to understand these shifts. The volume of births per hospital may be an important driver for the provision and experience of respectful maternity care. There is an urgent need for a system-wide approach to address respectful maternity care in the face of continuing disruptions owing to COVID-19. The dramatic shifts in the place of institutional deliveries must be matched by service capacity to provide respectful care and so enable positive experiences for all women and newborns as well as health care workers. More research is needed to investigate the effects of the pandemic on where women give birth and their provision and experience of respectful maternity care to inform a "building-back- better" approach in post-pandemic period. 


Acknowledgements: We would like to thank all the data coordinators and surveillance officers, hospital manager, nurs-
ing in-charge, all the nurses and support staff working in the labour and delivery unit during the unprecedented time.
We also thank Md. Moinuddin for statistical advice. We thank all the mothers and care-givers who consented to the RE-
FINE and SUSTAIN study.
Nepal Neonatal Network: Omkar Basnet, Srijana Sharma, Dr Avinash K Sunny, Dr Prajwal Paudel, Pratikshya Bhatta-
rai, Ankit Acharya, Prof. Anjani Kumar Jha, Dr Yasho Vardhan Pradhan, Dr Sushil Nath Pyakurel, Prof. Kiran Bajracha-
rya, Dr Sheela Verma, Dr Amit Bhandari, Dr Anjana KC Thapa, Dr Krishna Prasad Bista, Jhalak Sharma Paudel, Sangita
Khatri, and Leela Paudel.
Availability of supporting data: The dataset generated and analysed is not publicly available as it is part of larger quality
improvement projects but can be made available on reasonable request with data sharing agreement.
Funding: For this study no funding was available. The quality improvement studies, SUSTAIN and REFINE was funded
by Grand Challenges Canada and Laerdal Foundation for Acute Medicine, Norway.
Authorship contributions: AKC, MVK and WJG conceptualized the study. AKC and MVK made the first draft of the
manuscript. WJG, SSP, AS and RG reviewed and input in the first draft. HM, JG, BST, PP, KB, NJ, SA, DS, BG, LK reviewed
and input in the second draft. All authors read and approved of the final version.
Conflicts of interest: The authors completed the ICMJE Unified Competing Interest form (available upon request from
the corresponding author) and declare no conflicts of interest.
Additional material
Online Supplementary Document

1 Semaan A, Audet C, Huysmans E, Afolabi B, Assarag B, Banke-Thomas A, et al. Voices from the frontline: findings from a thematic analysis of a rapid online global survey of maternal and newborn health professionals facing the COVID-19 pandemic. BMJ Glob Health. 2020;5:e002967. Medline:32586891 doi:10.1136/bmjgh-2020-002967

2 Del Rio R, Dip Perez E, Marin Gabriel MA, Neo C-RG. Multi-centre study showed reduced compliance with the World Health Organization recommendations on exclusive breastfeeding during COVID-19. Acta Paediatr. 2021;110:935-6. Medline:33119915 doi:10.1111/apa.15642

3 Roberton T, Carter ED, Chou VB, Stegmuller AR, Jackson BD, Tam Y, et al. Early estimates of the indirect effects of the COVID-19 pandemic on maternal and child mortality in low-income and middle-income countries: a modelling study. Lancet Glob Health. 2020;8:e901-8. Medline:32405459 doi:10.1016/S2214-109X(20)30229-1

4 Graham WJ, Afolabi B, Benova L, Campbell OMR, Filippi V, Nakimuli A, et al. Protecting hard-won gains for mothers and newborns in low-income and middle-income countries in the face of COVID-19: call for a service safety net. BMJ Glob Health. 2020;5:e002754. Medline:32499220 doi:10.1136/bmjgh-2020-002754

5 Goyal M, Singh P, Singh K, Shekhar S, Agrawal N, Misra S. The effect of the COVID-19 pandemic on maternal health due to delay in seeking health care: Experience from a tertiary center. Int J Gynaecol Obstet. 2021;152:231-5. Medline:33128794 doi:10.1002/ijgo.13457

6 Kumari V, Mehta K, Choudhary R. COVID-19 outbreak and decreased hospitalisation of pregnant women in labour. Lancet Glob Health. 2020;8:e1116-7. Medline:32679037 doi:10.1016/S2214-109X(20)30319-3

7 Jackline Oluoch-Aridi, Tecla Chelagat, Mary M. Nyikuri, Joseph Onyango, Danice Guzman, Cindy Makanga, et al. COVID-19 Effect on Access to Maternal Health Services in Kenya. Frontiers in Global Women Health. 2020;1:599267. doi:10.3389/ fgwh.2020.599267

8 Pant S, Koirala S. Subedi M. Access to Maternal Health Services during COVID-19. Europasian Journal of Medical Sciences. 2020;2.

9 Arora KS, Mauch JT, Gibson KS. Labor and Delivery Visitor Policies During the COVID-19 Pandemic: Balancing Risks and Benefits. JAMA. 2020;323:2468-9. Medline:32442264 doi:10.1001/jama.2020.7563

10 Green L, Fateen D, Gupta D, McHale T, Nelson T, Mishori R. Providing women's health care during COVID-19: Personal and professional challenges faced by health workers. Int J Gynaecol Obstet. 2020;151:3-6. Medline:32692854 doi:10.1002/ ijgo. 13313

11 Yeo KT, Oei JL, De Luca D, Schmolzer GM, Guaran R, Palasanthiran P, et al. Review of guidelines and recommendations from 17 countries highlights the challenges that clinicians face caring for neonates born to mothers with COVID-19. Acta Paediatr. 2020;109:2192-207. Medline:32716579 doi:10.1111/apa.15495

12 Okereke M, Ukor NA, Adebisi YA, Ogunkola IO, Favour Iyagbaye E, Adiela Owhor G, et al. Impact of COVID-19 on access to healthcare in low- and middle-income countries: Current evidence and future recommendations. Int J Health Plann Manage. 2021;36:13-7. Medline:32857892 doi:10.1002/hpm.3067

13 Karkee R, Morgan A. Providing maternal health services during the COVID-19 pandemic in Nepal. Lancet Glob Health. 2020;8:e1243-4. Medline:32791116 doi:10.1016/S2214-109X(20)30350-8

14 Sarwer A, Javed B, Soto EB, Mashwani ZU. Impact of the COVID-19 pandemic on maternal health services in Pakistan. Int J Health Plann Manage. 2020;35:1306-10. Medline:32869363 doi:10.1002/hpm.3048 
15 Kc A, Gurung R, Kinney MV, Sunny AK, Moinuddin M, Basnet O, et al. Effect of the COVID-19 pandemic response on intrapartum care, stillbirth, and neonatal mortality outcomes in Nepal: a prospective observational study. Lancet Glob Health. 2020;8:e1273-81. Medline:32791117 doi:10.1016/S2214-109X(20)30345-4

16 Jacob CM, Briana DD, Di Renzo GC, Modi N, Bustreo F, Conti G, et al. Building resilient societies after COVID-19: the case for investing in maternal, neonatal, and child health. Lancet Public Health. 2020;5:e624-7. Medline:32971008 doi:10.1016/ S2468-2667(20)30200-0

17 Busch-Hallen J, Walters D, Rowe S, Chowdhury A, Arabi M. Impact of COVID-19 on maternal and child health. Lancet Glob Health. 2020;8:e1257. Medline:32758430 doi:10.1016/S2214-109X(20)30327-2

18 Jolivet RR, Warren CE, Sripad P, Ateva E, Gausman J, Mitchell K, et al. Upholding Rights Under COVID-19: The Respectful Maternity Care Charter. Health Hum Rights. 2020;22:391-4. Medline:32669827

19 World Health Organization. Coronavirus disease (COVID-19) technical guidance: Maintaining Essential Health Services and Systems. Geneva: 2020.

20 United Nations. A human rights-based approach to mistreatment and violence against women in reproductive health services with a focus on childbirth and obstetric violence: note / by the Secretary-General. New York: United Nations, 2019.

21 Khosla R, Zampas C, Vogel JP, Bohren MA, Roseman M, Erdman JN. International Human Rights and the Mistreatment of Women During Childbirth. Health Hum Rights. 2016;18:131-43. Medline:28559681

22 White Ribbon Alliance. Respectful Maternity Care Charter: Universal Rights of Mothers and Newborns. Washington: 2019.

23 World Health Organization. Standards for improving quality of maternal and newborn care in health facilities. Geneva: 2016.

24 World Health Organization. WHO recommendations: intrapartum care for a positive childbirth experience. Geneva: 2018.

25 Delamou A, Ayadi AME, Sidibe S, Delvaux T, Camara BS, Sandouno SD, et al. Effect of Ebola virus disease on maternal and child health services in Guinea: a retrospective observational cohort study. Lancet Glob Health. 2017;5:e448-57. Medline:28237252 doi:10.1016/S2214-109X(17)30078-5

26 Brolin Ribacke KJ, van Duinen AJ, Nordenstedt H, Hoijer J, Molnes R, Froseth TW, et al. The Impact of the West Africa Ebola Outbreak on Obstetric Health Care in Sierra Leone. PLoS One. 2016;11:e0150080. Medline:26910462 doi:10.1371/journal. pone. 0150080

27 Lori JR, Munro-Kramer ML, Shifman J, Amarah PNM, Williams G. Patient Satisfaction With Maternity Waiting Homes in Liberia: A Case Study During the Ebola Outbreak. J Midwifery Womens Health. 2017;62:163-71. Medline:28376559 doi:10.1111/ jmwh. 12600

28 Afulani P, Diamond-Smith N. Responsive and respectful maternity care needs protection during COVID-19 crisis. The Conversation. London: 2020.

29 Michelle M. Dynes LM, Tamba Sam, Mohamed Alex Vandi, Barbara Tomczyk. Perceptions of the Risk for Ebola and Health Facility Use Among Health Workers and Pregnant and Lactating Women — Kenema District, Sierra Leone, September 2014. Morbidity and Mortality Weekly Report (MMWR), Center for Disease Control and Prevention. 2015;63.

30 Theuring S, Koroma AP, Harms G. "In the hospital, there will be nobody to pamper me": a qualitative assessment on barriers to facility-based delivery in post-Ebola Sierra Leone. Reprod Health. 2018;15:155. Medline:30219070 doi:10.1186/s12978-018-0601-9

31 Armocida B, Formenti B, Ussai S, Palestra F, Missoni E. The Italian health system and the COVID-19 challenge. Lancet Public Health. 2020;5:e253. Medline:32220653 doi:10.1016/S2468-2667(20)30074-8

32 Mubiri P, Kajjo D, Okuga M, Marchant T, Peterson S, Waiswa P, et al. Bypassing or successful referral? A population-based study of reasons why women travel far for childbirth in Eastern Uganda. BMC Pregnancy Childbirth. 2020;20:497. Medline:32854629 doi:10.1186/s12884-020-03194-2

33 Hanson C, Waiswa P, Pembe A, Sandall J, Schellenberg J. Health system redesign for equity in maternal and newborn health must be codesigned, country led, adapted to context and fit for purpose. BMJ Glob Health. 2020;5:e003748. Medline:33055095 doi:10.1136/bmjgh-2020-003748

34 Government of Nepal. Safe Motherhood and Reproductive Health Right Act, 2018. Kathmandu: 2018.

35 Collins. Collins Dictionary. Glasgow: Collins; 2020.

36 Gurung R, Gurung A, Basnet O, Eilevstjonn J, Myklebust H, Girnary S, et al. REFINE (Rapid Feedback for quality Improvement in Neonatal rEsuscitation): an observational study of neonatal resuscitation training and practice in a tertiary hospital in Nepal. BMC Pregnancy Childbirth. 2020;20:756. Medline:33272242 doi:10.1186/s12884-020-03456-z

37 Gurung R, Jha AK, Pyakurel S, Gurung A, Litorp H, Wrammert J, et al. Scaling Up Safer Birth Bundle Through Quality Improvement in Nepal (SUSTAIN)-a stepped wedge cluster randomized controlled trial in public hospitals. Implement Sci. 2019;14:65. Medline:31217028 doi:10.1186/s13012-019-0917-z

38 Kc A, Ewald U, Basnet O, Gurung A, Pyakuryal SN, Jha BK, et al. Effect of a scaled-up neonatal resuscitation quality improvement package on intrapartum-related mortality in Nepal: A stepped-wedge cluster randomized controlled trial. PLoS Med. 2019;16:e1002900. Medline:31498784 doi:10.1371/journal.pmed.1002900

39 Stang AS, Crotts J, Johnson DW, Hartling L, Guttmann A. Crowding measures associated with the quality of emergency department care: a systematic review. Acad Emerg Med. 2015;22:643-56. Medline:25996053 doi:10.1111/acem.12682

40 Diana H, Bowser K. Exploring evidence for disrespect and abuse in facility-based childbirth: report of a landscape analysis. Washington DC: United States Agency for International Development (USAID); 2010.

41 Subedi M. Caste system: Theories and practices in Nepal. Himal J Sociol Anthropol. 2011;4:134-59. doi:10.3126/hjsa.v4i0.4672

42 Family Health Division DoHS, Ministry of Health and Population. National Safe Motherhood And Newborn Health-Long Term Plan (2006-2017). Kathmandu, Nepal: 2006.

43 Mehata S, Paudel YR, Dariang M, Aryal KK, Paudel S, Mehta R, et al. Factors determining satisfaction among facility-based maternity clients in Nepal. BMC Pregnancy Childbirth. 2017;17:319. Medline:28946851 doi:10.1186/s12884-017-1532-0 
44 Roder-DeWan S, Nimako K, Twum-Danso NAY, Amatya A, Langer A, Kruk M. Health system redesign for maternal and newborn survival: rethinking care models to close the global equity gap. BMJ Glob Health. 2020;5:e002539. Medline:33055093 doi:10.1136/bmjgh-2020-002539

45 Orpin J, Puthussery S, Burden B. Healthcare providers' perspectives of disrespect and abuse in maternity care facilities in Nigeria: a qualitative study. Int J Public Health. 2019;64:1291-9. Medline:31673736 doi:10.1007/s00038-019-01306-0

46 Karkee R, Lee AH, Binns CW. Bypassing birth centres for childbirth: an analysis of data from a community-based prospective cohort study in Nepal. Health Policy Plan. 2015;30:1-7. Medline:24270520 doi:10.1093/heapol/czt090

47 Moyer CA, Sakyi KS, Sacks E, Compton SD, Lori JR, Williams JEO. COVID-19 is increasing Ghanaian pregnant women's anxiety and reducing healthcare seeking. Int J Gynaecol Obstet. 2021;152:444-5. Medline:33222215 doi:10.1002/ijgo.13487

48 Bohren MA, Mehrtash H, Fawole B, Maung TM, Balde MD, Maya E, et al. How women are treated during facility-based childbirth in four countries: a cross-sectional study with labour observations and community-based surveys. Lancet. 2019;394:175063. Medline:31604660 doi:10.1016/S0140-6736(19)31992-0

49 Sacks E, Mehrtash H, Bohren M, Balde MD, Vogel JP, Adu-Bonsaffoh K, et al. The first $2 \mathrm{~h}$ after birth: prevalence and factors associated with neonatal care practices from a multicountry, facility-based, observational study. Lancet Glob Health. 2021;9:e7280. Medline:33189189 doi:10.1016/S2214-109X(20)30422-8

50 Bohren MA, Vogel JP, Hunter EC, Lutsiv O, Makh SK, Souza JP, et al. The Mistreatment of Women during Childbirth in Health Facilities Globally: A Mixed-Methods Systematic Review. PLoS Med. 2015;12:e1001847. Medline:26126110 doi:10.1371/ journal.pmed.1001847

51 World Health Organization. WHO's Statement on The prevention and elimination of disrespect and abuse during facility-based childbirth. Geneva: WHO; 2016. 